Article

\title{
Improving Fatigue Performance of Laser-Welded 2024-T3 Aluminum Alloy Using Dry Laser Peening
}

\author{
Tomokazu Sano ${ }^{1, *} \mathbb{0}$, Takayuki Eimura ${ }^{1}$, Akio Hirose ${ }^{1}$, Yosuke Kawahito ${ }^{2}$, Seiji Katayama ${ }^{2}$, \\ Kazuto Arakawa ${ }^{3}$, Kiyotaka Masaki ${ }^{4}$, Ayumi Shiro ${ }^{5}$, Takahisa Shobu ${ }^{6}$ and Yuji Sano ${ }^{7,8}$ (D) \\ 1 Division of Materials and Manufacturing Science, Graduate School of Engineering, Osaka University, \\ 2-1 Yamada-oka, Suita 565-0871, Japan; toyahi31@gmail.com (T.E.); hirose@mapse.eng.osaka-u.ac.jp (A.H.) \\ 2 Joining and Welding Research Institute, Osaka University, 11-1 Mihogaoka, Ibaraki 567-0047, Japan; \\ kawahito@jwri.osaka-u.ac.jp (Y.K.); katayama@jwri.osaka-u.ac.jp (S.K.) \\ 3 Interdisciplinary Faculty of Science and Engineering, Shimane University, 1060 Nishikawatsu-cho, \\ Matsue 690-8504, Japan; arakawa@riko.shimane-u.ac.jp \\ 4 National Institute of Technology, Okinawa College, 905 Henoko, Nago 905-2192, Japan; \\ masaki-k@okinawa-ct.ac.jp \\ 5 Quantum Beam Science Research Directorate, National Institute for Quantum and Radiological Science and \\ Technology, Kouto, Sayo 679-5148, Japan; shiro.ayumi@qst.go.jp \\ 6 Materials Sciences Research Center, Japan Atomic Energy Agency, Kouto, Sayo 679-5148, Japan; \\ shobu@spring8.or.jp \\ 7 Division of Research Innovation and Collaboration, Institute for Molecular Science, National Institutes of \\ Natural Sciences, 38 Nishigo-Naka, Myodaiji, Okazaki 444-8585, Japan; yuji-sano@ims.ac.jp \\ 8 Department of Quantum Beam Physics, Institute of Scientific and Industrial Research, Osaka University, \\ 8-1 Mihogaoka 567-0047, Japan \\ * Correspondence: sano@mapse.eng.osaka-u.ac.jp
}

Received: 23 September 2019; Accepted: 4 November 2019; Published: 6 November 2019

\begin{abstract}
The purpose of the present study was to verify the effectiveness of dry laser peening (DryLP), which is the peening technique without a sacrificial overlay under atmospheric conditions using femtosecond laser pulses on the mechanical properties such as hardness, residual stress, and fatigue performance of laser-welded 2024 aluminum alloy containing welding defects such as undercuts and blowholes. After DryLP treatment of the laser-welded 2024 aluminum alloy, the softened weld metal recovered to the original hardness of base metal, while residual tensile stress in the weld metal and heat-affected zone changed to compressive stresses. As a result, DryLP treatment improved the fatigue performances of welded specimens with and without the weld reinforcement almost equally. The fatigue life almost doubled at a stress amplitude of $180 \mathrm{MPa}$ and increased by a factor of more than 50 at $120 \mathrm{MPa}$. DryLP was found to be more effective for improving the fatigue performance of laser-welded aluminum specimens with welding defects at lower stress amplitudes, as stress concentration at the defects did not significantly influence the fatigue performance.
\end{abstract}

Keywords: dry laser peening; femtosecond laser; shock wave; laser welding; 2024 aluminum alloy

\section{Introduction}

Laser peening (LP), or laser shock peening (LSP), is a surface treatment method used to improve mechanical properties, such as fatigue performance and corrosion resistance, by hardening the material and adding compressive residual stresses on the surfaces via a laser-driven shock wave that causes plastic deformation of the material [1-5]. In recent years, the application of LP has been extended to the aerospace, nuclear, automotive, and biomedical industries [6]. The LP process can efficiently induce plasticity because of the high-strain-rate deformation caused by shock compression. Unlike other 
peening processes, such as shot peening, hammer peening, and ultrasonic peening, LP is a noncontact process that does not contaminate the sample.

During LP processing, the material surface is irradiated with a laser pulse passed through a transparent plasma confinement medium, such as water or glass, resulting in explosive ablation of the material. The material is plastically deformed by a shock wave formed by the recoil force of plasma expansion during ablation, which propagates into the material. An opaque overlay, such as paint, black tape, or metal foils, is conventionally applied to the material surface to avoid thermal effects, such as excessive temperature increase or melting, due to the high energy of the laser itself or laser-generated plasma. A LP method that does not require such a coating has been developed using an irradiation source formed by overlapping low-energy pulses [7,8]. Furthermore, a dry LP (DryLP) technique has been developed that does not require a sacrificial overlay and is performed under ambient conditions, where the material is directly irradiated using femtosecond laser pulses [9-11]. Although femtosecond laser pulses have a small pulse energy, the electric field is so strong that the material is explosively ablated without requiring the opaque overlay or the plasma confinement medium [12,13]. This induces a plastic shock wave strong enough to cause shock effects in the material [14-19].

Here, we proposed the application of DryLP to improve the mechanical properties of laser-welded 2024 aluminum alloy. LP is generally effective for improving the fatigue performance of arc-welded [20] and friction stir-welded joints [21-23]. The fatigue performance of welded precipitation-strengthened aluminum alloys, such as the 2000,6000, and 7000 series, were worse than the corresponding base material (BM) because of the softening of the weld metal (WM), heat-affected zone (HAZ), and residual tensile stress on the surface after welding [24,25]. Therefore, in recent years, friction stir welding (FSW) has been widely used to join precipitation-strengthened aluminum alloys because it results in only a small decrease in the strength of the weld joint and small distortion of the joint after welding [26-28], although the welding speed is relatively low. Laser welding is a high-speed welding method that has been used for achieving high-productivity welding of precipitation-strengthened aluminum alloys [29,30]. Although the weldability of 2024 aluminum alloy is generally low, fast full-penetration welding of this alloy using highly focused fiber laser achieved weld joints with smaller HAZ regions and no cracking [31]. However, areas of WM with reduced strength exist, and avoiding generation of blowholes in the laser-welded joints is difficult. Although the thickness with the compressive residual stress induced by DryLP process is almost one-tenth of conventional LP methods $[9,10]$, this method was shown to be effective for FSW-processed 7075-T73 aluminum alloy, where the stir zone, thermo-mechanically affected zone, and HAZ were softened, but no welding defects occurred, confirming that the fatigue performance was better than that of the BM at lower stress amplitude after DryLP treatment. However, the effectiveness of DryLP on welded precipitation-strengthened aluminum alloy containing welding defects has never been investigated. Hence, the purpose of the present study is to verify the effectiveness of DryLP for laser-welded 2024 aluminum alloy containing welding defects by investigating the mechanical properties.

\section{Experimental Method}

A 2024-T3 aluminum alloy with thickness of $3 \mathrm{~mm}$ was used. The chemical composition of this alloy is shown in Table 1 . The original alloy had a $0.2 \%$ proof stress of $334 \mathrm{MPa}$, tensile strength of $464 \mathrm{MPa}$, and elongation of $21.8 \%$.

Table 1. Chemical composition of 2024-T3 aluminum alloy used in this study (mass $\%$ ).

\begin{tabular}{cccccccccc}
\hline Si & Fe & Cu & Mn & Mg & Cr & Zn & Ti & Others & Al \\
\hline 0.02 & 0.05 & 4.4 & 0.55 & 1.4 & 0.00 & 0.02 & 0.01 & 0.01 & Bal. \\
\hline
\end{tabular}

A single-mode fiber laser (IPG Photonics, YLS-2000-SM, Japan, wavelength: $1070 \mathrm{~nm}, \mathrm{CW}$ ) was used for full-penetration bead-on-plate welding of the aluminum alloy, as shown in Figure 1a. The fiber 
diameter was $14 \mu \mathrm{m}$ and we used a laser power of $2.0 \mathrm{~kW}$. The laser was focused on the alloy surface with a spot size of $54 \mu \mathrm{m}$. Ar was used for shielding gas with a flow rate of $30 \mathrm{~L} / \mathrm{min}$. A welding speed of $2.5 \mathrm{~m} / \mathrm{min}$ was used. The top and bottom surfaces of the laser-welded specimens were observed using an optical digital microscopy (Hirox, KH-7700, Japan). The cross-section of the weld bead was observed using optical microscopy (Olympus, SZX7, Tokyo, Japan).

(a)

\section{Weld bead}

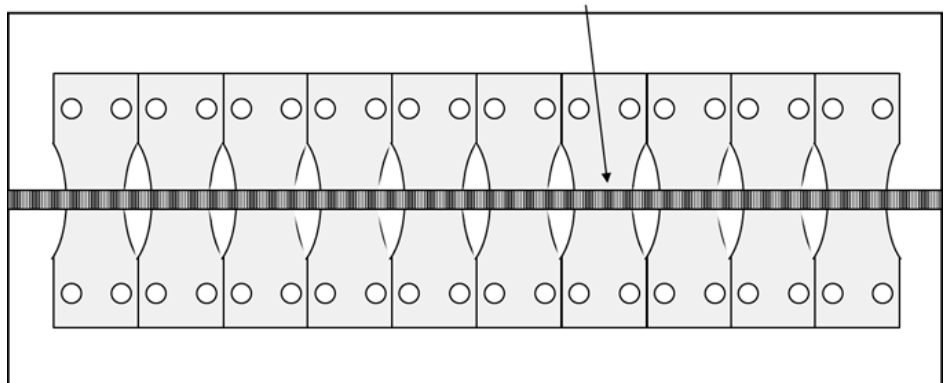

(b) Femtosecond laser pulse $800 \mathrm{~nm}, 120 \mathrm{fs}$

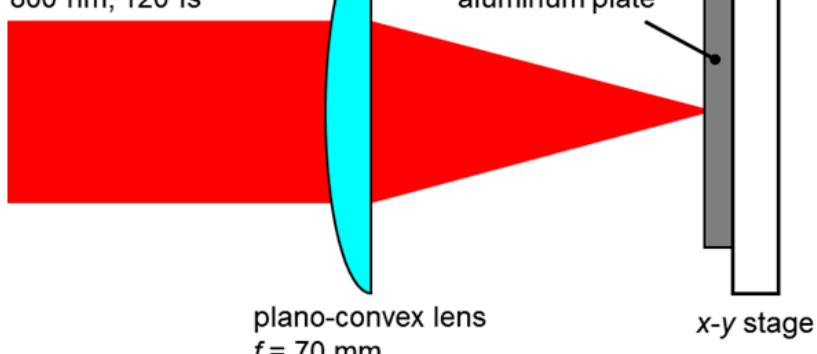

$f=70 \mathrm{~mm}$

(c)
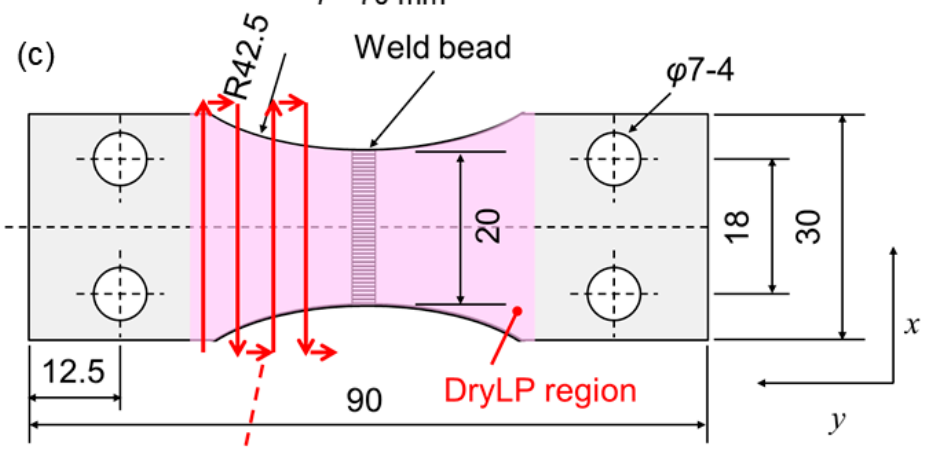

Scan direction of

femtosecond laser pulses

(Unit: $\mathrm{mm}$ )

Figure 1. Schematic illustrations of the experimental procedures. (a) Full-penetration bead-on-plate laser welding and preparation of fatigue test specimens cut from the laser-welded plate. (b) Dry laser peening (DryLP) process using femtosecond laser pulses. (c) Geometry of the fatigue test specimens with the weld bead located in the center. DryLP was performed using an $\mathrm{x}-\mathrm{y}$ automatic stage which sequentially moved the specimen in a serpentine pattern, as indicated by the red arrows.

Then, the laser-welded specimens were subjected to DryLP in air. The peening was performed 15 months after welding to allow the completion of natural aging. As shown in Figure 1b,c, femtosecond laser pulses with a wavelength of $800 \mathrm{~nm}$, pulse duration of $130 \mathrm{fs}$, and pulse energy of $0.6 \mathrm{~mJ}$ (Spectra-Physics, Spitfire, Japan) were focused using a plano-convex lens with focal length of $70 \mathrm{~mm}$ onto the specimen. The laser pulses were overlapped, with a coverage of $692 \%$, which was shown to be the most effective condition for DryLP of 2024-T3 aluminum alloy [9]. A detailed description of the DryLP process was provided in the previous study. 
For the preparation of specimens for hardness tests, the weld reinforcement was removed and electropolished in $20 \%$ sulfuric acid-methanol electrolyte for $30 \mathrm{~s}$ to remove the work-strained layer before DryLP treatment. The hardness of the top surface was measured using a Vickers hardness tester (Mitsutoyo, HM-221, Kawasaki, Japan) with a load of $1.96 \mathrm{~N}$ and loading time of $15 \mathrm{~s}$.

For the preparation of specimens for residual stress measurement, DryLP treatment was conducted on as-welded specimens without removing the weld reinforcement. Depth profiling of the residual stress which was normal to the weld bead in the specimens was conducted nondestructively using the BL22XU beamline at SPring-8 [32], using the strain scanning method [33] with monochromatic X-rays with a photon energy of $30.013 \mathrm{keV}$, as shown in Figure 2. A CdTe detector was used for the measurements. The residual stress $\sigma$ was estimated using $\sigma=E\left(d-d_{0}\right) / d_{0}$, where $E$ is the Young's modulus of $61.7 \mathrm{GPa}, d$ is the d-spacing of the (311) plane of aluminum in the welded or DryLPed specimens, and $d_{0}$ is the d-spacing of the (311) plane in the BM of $0.12196 \mathrm{~nm}$. The $\mathrm{d}$-spacing of the (311) plane parallel to the weld bead in the gauge volume was measured, as shown in Figure 2a,b. The widths of both the incident and receiving slits were $0.2 \mathrm{~mm}$. For the surface measurements, the heights of these slits were $50 \mu \mathrm{m}$. For depth profiling, the slit heights, which determine the depth resolution, were $10 \mu \mathrm{m}$ from the surface to a depth of $40 \mu \mathrm{m}$, and the slit heights were $30 \mu \mathrm{m}$ deeper than a depth of $40 \mu \mathrm{m}$. The d-spacings of the (311) plane of the WM, below the weld toe, and in the HAZ were measured, as shown in Figure 2c.

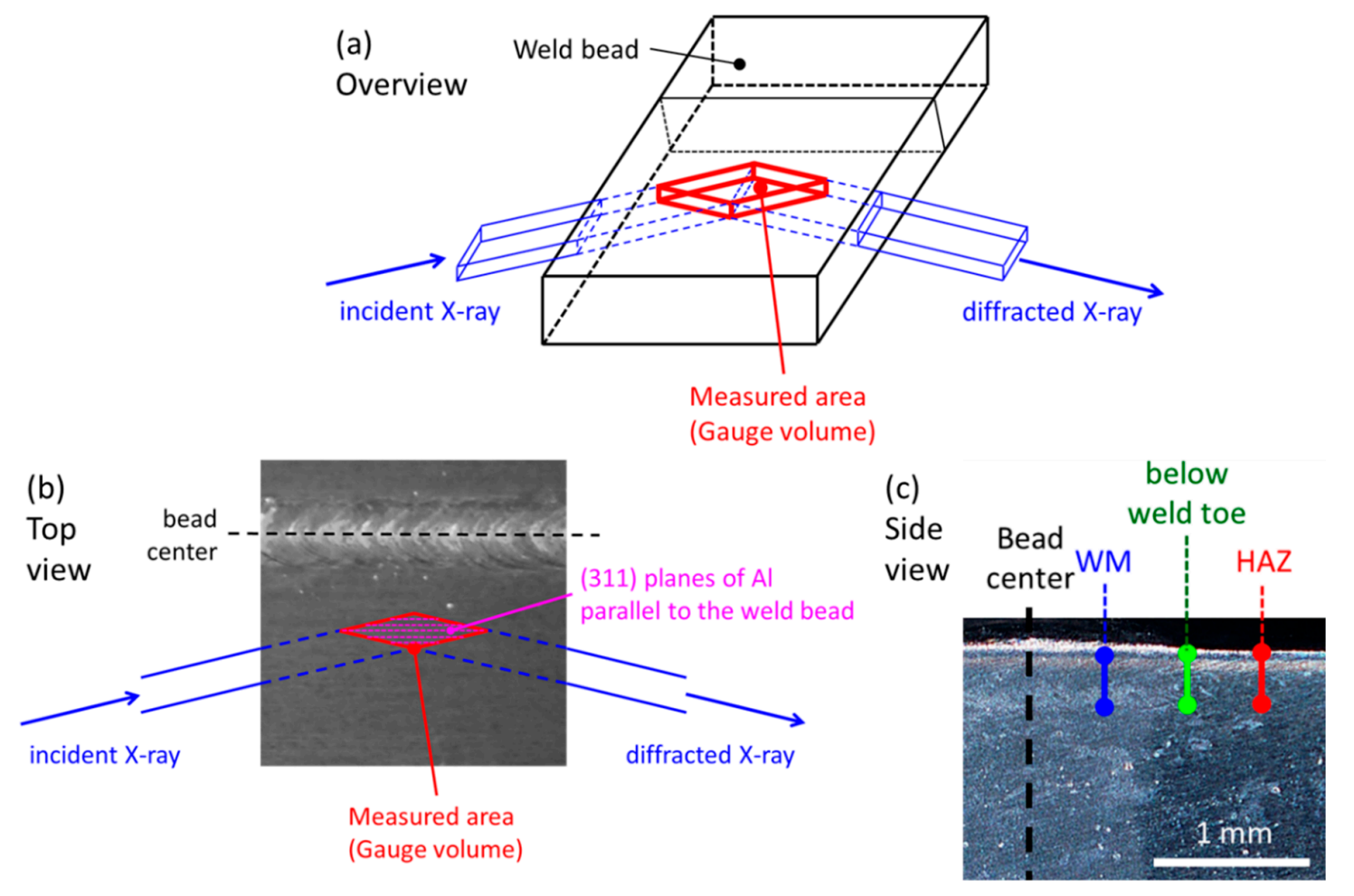

Figure 2. Schematic illustrations of (a) overview, (b) top, and (c) side views of residual stress measurements using the strain scanning method with synchrotron $\mathrm{X}$-rays.

Four kinds of specimens for fatigue testing were prepared: (i) As-welded specimen; (ii) reinforcement-removed welded specimen; (iii) DryLPed welded specimen; and (iv) DryLPed reinforcement-removed welded specimen. The stress concentration influenced the fatigue properties of the as-welded specimen due to both reinforcements and undercuts. Hence, to investigate the stress concentration only influenced by the undercuts, the reinforcements were removed. The reinforcements were removed using diamond pastes with a particle size of $1 \mu \mathrm{m}$. These specimens were cut from the laser-welded specimen, as shown in Figure 1a. DryLP was conducted on both surfaces of the 
laser-welded specimen, as shown in Figure 1b. Plane bending fatigue tests (PBF-30, Tokyo Koki, Tokyo, Japan) were conducted at a cyclic speed of 1400 cycles/min with a constant strain amplitude and a stress ratio of $R=-1$ in air at room temperature based on Little's method [34]. The stress ratio of $R=-1$ was selected to indicate the effectiveness of the DryLP more clearly because both surfaces were treated. The fracture surfaces were observed using optical microscopy (Olympus, SZX7, Tokyo, Japan) and scanning electron microscopy (SEM; Hitachi, S-3000H, Tokyo, Japan).

The microstructures were observed to estimate dislocation densities in the specimens using a transmission electron microscopy (TEM; JEOL JEM-2010, Tokyo, Japan) with an acceleration voltage of $200 \mathrm{kV}$. For TEM observations, a small piece of the cross-section was thinned using a 30-keV-focused Ga-ion beam (Hitachi, FB-2000A, Tokyo, Japan).

\section{Results and Discussion}

\subsection{Laser Welding}

Optical microscopy images of the top and bottom rear surfaces of the laser-welded specimens are shown in Figure 3a,b. Although no cracks were observed on the surfaces, some pores existed on the top surface and some undercuts (indicated by yellow arrows in the figures) were found on both surfaces. The cross-section of the weld bead shows that full-penetration welding was achieved, where the reinforcement did not show any cracks (Figure $3 \mathrm{c}$ ). The bead widths on the top and rear surfaces were around $2.0 \mathrm{~mm}$ and $1.2 \mathrm{~mm}$, respectively. The optical microscopy image of the bottom surface of the reinforcement-removed welded specimen is shown in Figure $3 \mathrm{~d}$, where the yellow arrows indicate the undercuts.
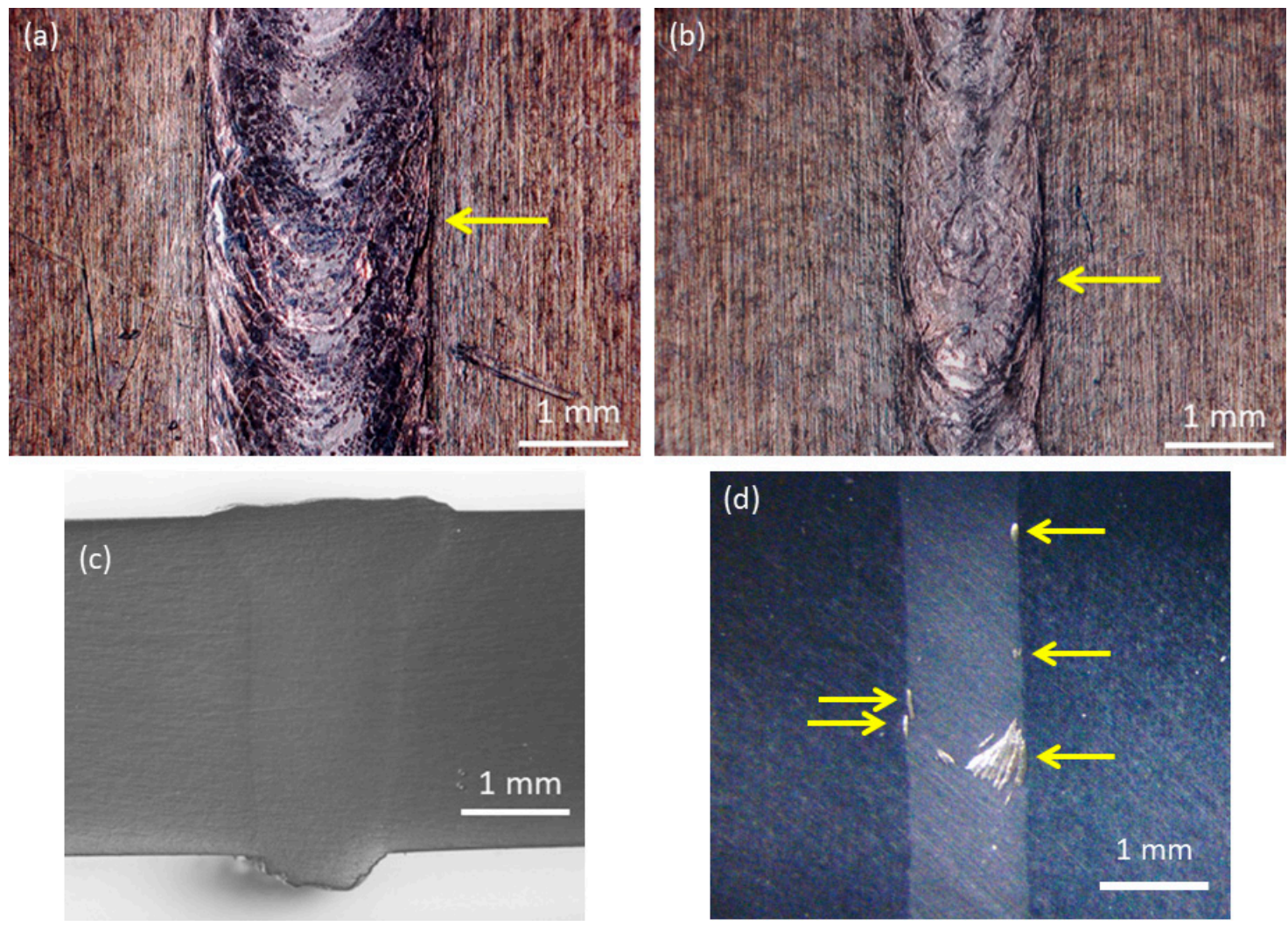

Figure 3. Optical microscopy images of (a) top surface, (b) bottom surface, (c) cross-section of the laser-weld bead, and (d) bottom surface of reinforcement-removed welded specimen. 


\subsection{Hardness}

The results of the hardness tests for the samples with the reinforcement removed are shown in Figure 4. Before DryLP, the hardness of the BM was $138 \mathrm{HV}$, while that on the surface of the WM was $\sim 100 \mathrm{HV}$. It was reported that this decrease in hardness is due to i) the segregation of the strengthening elements such as magnesium, copper, and their intermetallic compounds; ii) formation and growth of non-strengthening coarse precipitates; iii) dissolution of strengthening precipitates; iv) uniform re-distribution of precipitating elements; and v) vaporization of low boiling point magnesium during heating and the following freezing due to the fast cooling rates [35-37], resulting in fewer precipitates being formed, even after natural aging for 15 months. The hardness of the HAZ in this specimen was around $130 \mathrm{HV}$ (similar to the BM) because of the dissolution of precipitates and overaging $[35,38]$. After DryLP, the hardness of all areas of the sample increased compared to that of the as-welded sample. The hardness of the WM was similar to that of the BM before peening, while the hardness of the HAZ and BM after DryLP was around $178 \mathrm{HV}$.

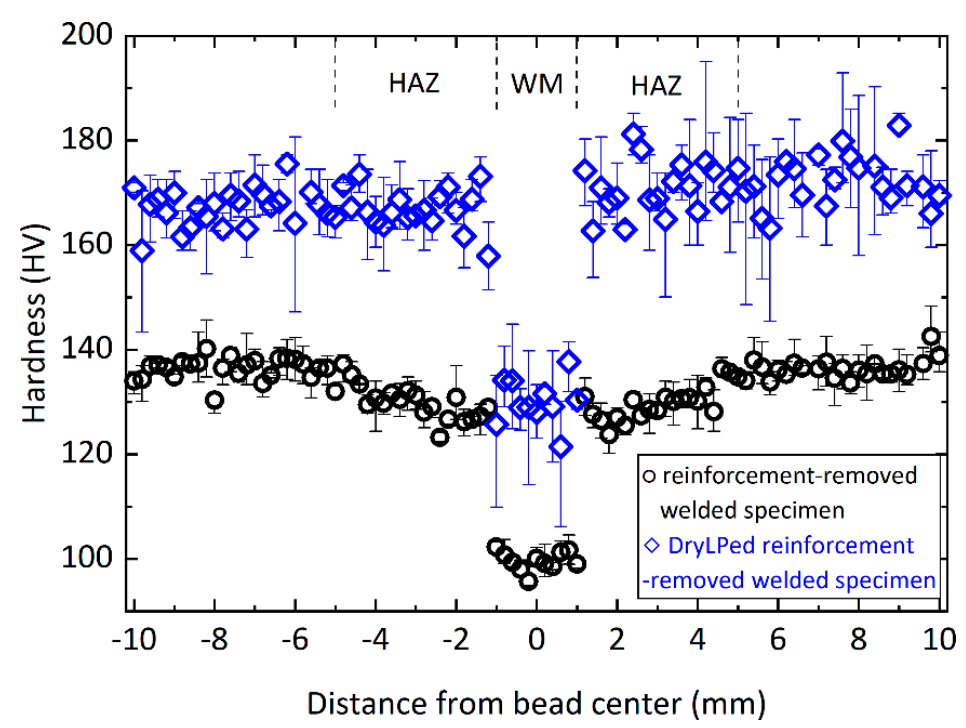

Figure 4. Hardness distributions over the surfaces of welded samples with the reinforcement removed, before, and after DryLP treatment. Error bar indicates the maximum and minimum values.

\subsection{Residual Stress}

Residual stress curves of the top surface before and after DryLP treatment of the laser-welded specimens are shown in Figure 5a. The residual stress in the WM and HAZ areas of the as-welded specimen were tensile, while other areas had compressive stresses, which is a typical residual stress distribution for welded joints. This tensile residual surface stress in the WM and HAZ areas changed to compressive stress after DryLP treatment, while the magnitude of the compressive residual stresses outside these areas increased. The depth profiles of the residual stress in the WM, below the weld toe, and in the HAZ before and after DryLP treatment are shown in Figure $5 b-d$. The tensile residual stresses in the WM, below the weld toe, and in the HAZ were observed to a depth of $\sim 300 \mu \mathrm{m}$ from the weld center in the as-welded specimen. These tensile residual stresses inside the material between the surface and a depth of $\sim 100 \mu \mathrm{m}$ changed to compressive stresses after DryLP, which is comparable to the thickness of the compressive layer in the DryLPed BM [9]. 

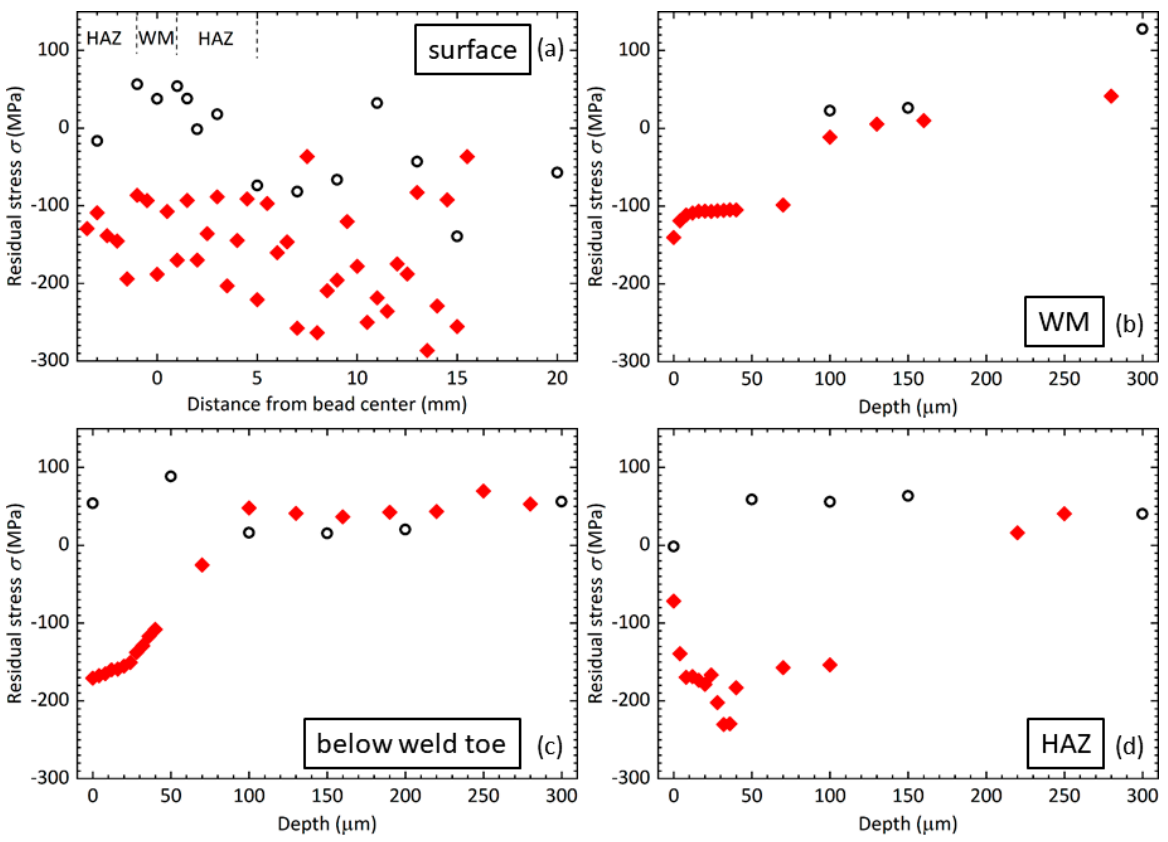

$\mathrm{O}$ as-welded specimen, $\bullet$ DryLPed welded specimen

Figure 5. (a) Residual stress distributions along the surface (up to 50- $\mu \mathrm{m}$ depth). Depth profiles of the residual stress in the (b) WM, (c) below the weld toe, and (d) in the HAZ of laser-welded specimens before and after DryLP.

\subsection{Fatigue Performance}

The results of the fatigue tests are shown in Figure 6. The fitted curves for each specimen were obtained using Stromeyer's expression, $\log (\sigma-a)=-b \log N+c$, where $\sigma$ is the stress amplitude, $N$ is the number of cycles to failure, and $a, b$, and $c$ are the fitting parameters. The fatigue performances of the as-welded specimens with and without reinforcement were worse than that of the BM. Although the fatigue lives of these specimens at a stress amplitude of $180 \mathrm{MPa}$ were almost the same, that of the reinforcement-removed welded specimen was shorter than that of the as-welded specimen at $120 \mathrm{MPa}$. After DryLP treatment, the fatigue performances of the specimens with and without reinforcement were enhanced to a similar degree. The fatigue life increased by a factor of almost two at a stress amplitude of $180 \mathrm{MPa}$ and more than 50 times at $120 \mathrm{MPa}$, which indicates that the DryLP treatment is more effective at lower stress amplitudes.

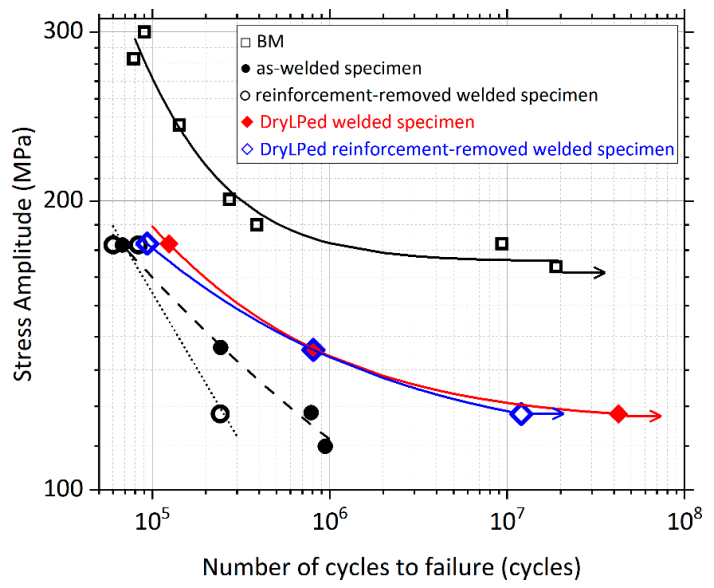

Figure 6. Results of fatigue tests for the base material (BM) and as-welded specimens (with and without reinforcement) before and after DryLP treatment. 
The fracture surfaces of samples broken at $120 \mathrm{MPa}$ and $180 \mathrm{MPa}$ are shown in Figure 7, where the red arrows indicate crack initiation sites. The crack initiation sites for any specimens, such as as-welded and reinforcement-removed specimens before and after DryLP treatment, are undercuts, not blowholes. The fractures initiated at the boundary between the WM and HAZ for all specimens, regardless of DryLP treatment or the existence of weld reinforcement. Cracks initiated at undercuts are shown in the magnified views of the surfaces in Figure $7 \mathrm{~g}$.

(a) as-welded specimen broken at $120 \mathrm{MPa}$

(b) reinforcement-removed welded specimen broken at $120 \mathrm{MPa}$

(c) as-welded specimen broken at $180 \mathrm{MPa}$

(d) reinforcement-removed welded specimen broken at $180 \mathrm{MPa}$
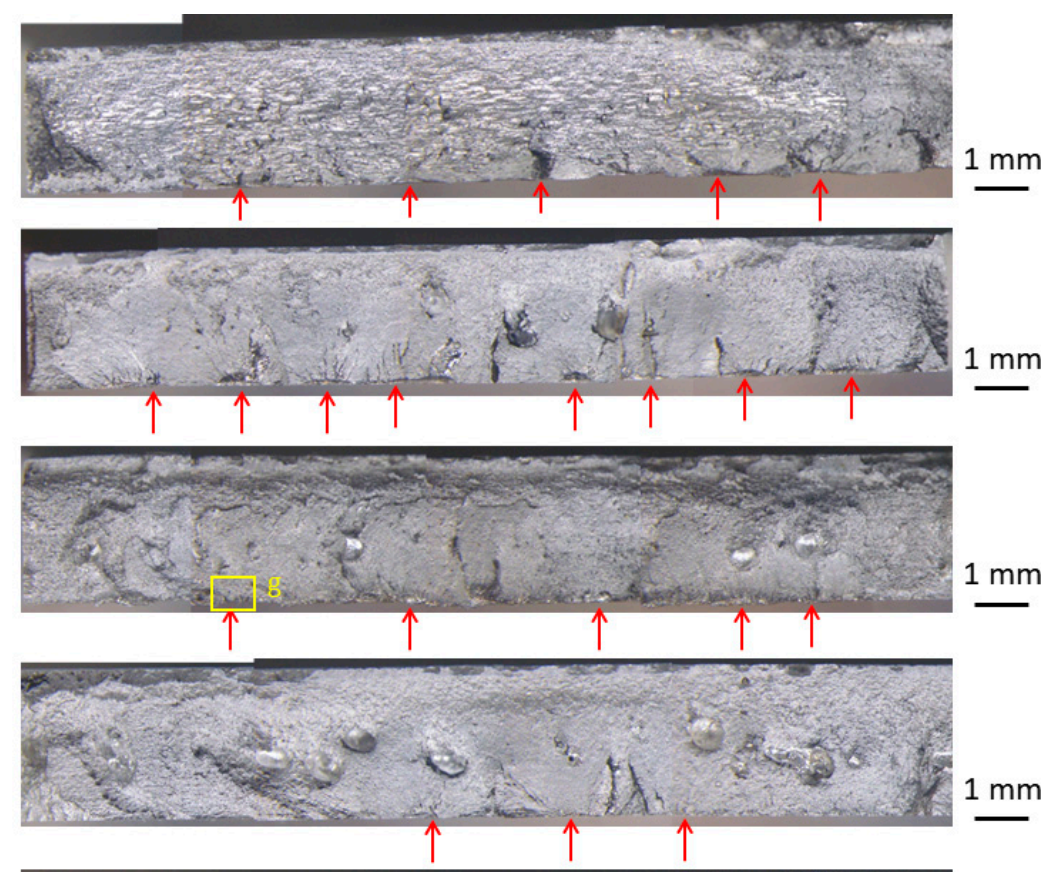

(e) DryLPed welded specimen broken at $180 \mathrm{MPa}$

(f) DryLPed reinforcementremoved welded specimen broken at $180 \mathrm{MPa}$
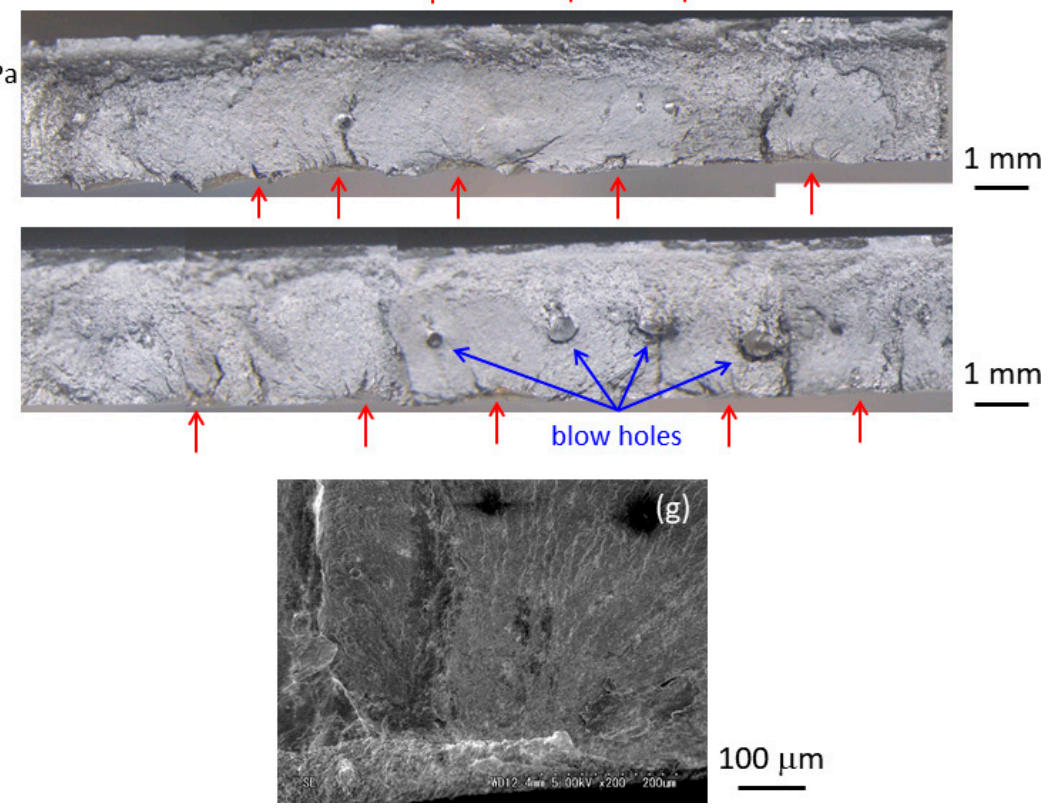

Figure 7. Fracture surfaces of the welded specimens. (a) As-welded specimen broken at $120 \mathrm{MPa}$, (b) reinforcement-removed welded specimen broken at $120 \mathrm{MPa}$, (c) as-welded specimen broken at $180 \mathrm{MPa}$, (d) reinforcement-removed welded specimen broken at $180 \mathrm{MPa}$, (e) DryLPed welded specimen broken at $180 \mathrm{MPa}$, (f) DryLPed reinforcement-removed welded specimen broken at $180 \mathrm{MPa}$. (g) Magnified image of a typical crack initiation site, as indicated by the yellow box in (c). 


\subsection{Microstructure in WM}

Bright-field TEM images of the region $\sim 10 \mu \mathrm{m}$ below the surface in the WM of as-welded and DryLPed specimens (with reinforcement) are shown in Figure 8. The incident electron beam direction was nearly parallel to the [110] direction of $\mathrm{Al}$, where the $\{111\}$ reflection of $\mathrm{Al}$ was excited. The dislocations were observed as the darker areas. The dislocation density was estimated using Keh's equation, $\rho=\left(n_{1} / L_{1}+n_{2} / L_{2}\right) / t$, where $\rho$ is the dislocation density, $n_{1}$ and $n_{2}$ is the number of intersection points between the dislocation lines and the vertical and horizontal grid lines drawn on the TEM image, respectively, $L_{1}$ and $L_{2}$ is the total length of the vertical and horizontal grid lines, respectively, and $t$ is the thickness of the TEM sample [39]. The dislocation densities of these samples before and after DryLP treatment were estimated as $1.0 \times 10^{14} \mathrm{~m}^{-2}$ and $5.1 \times 10^{14} \mathrm{~m}^{-2}$, respectively. This indicates that DryLP plastically deformed the WM, resulting in hardening and inducing compressive residual stress.
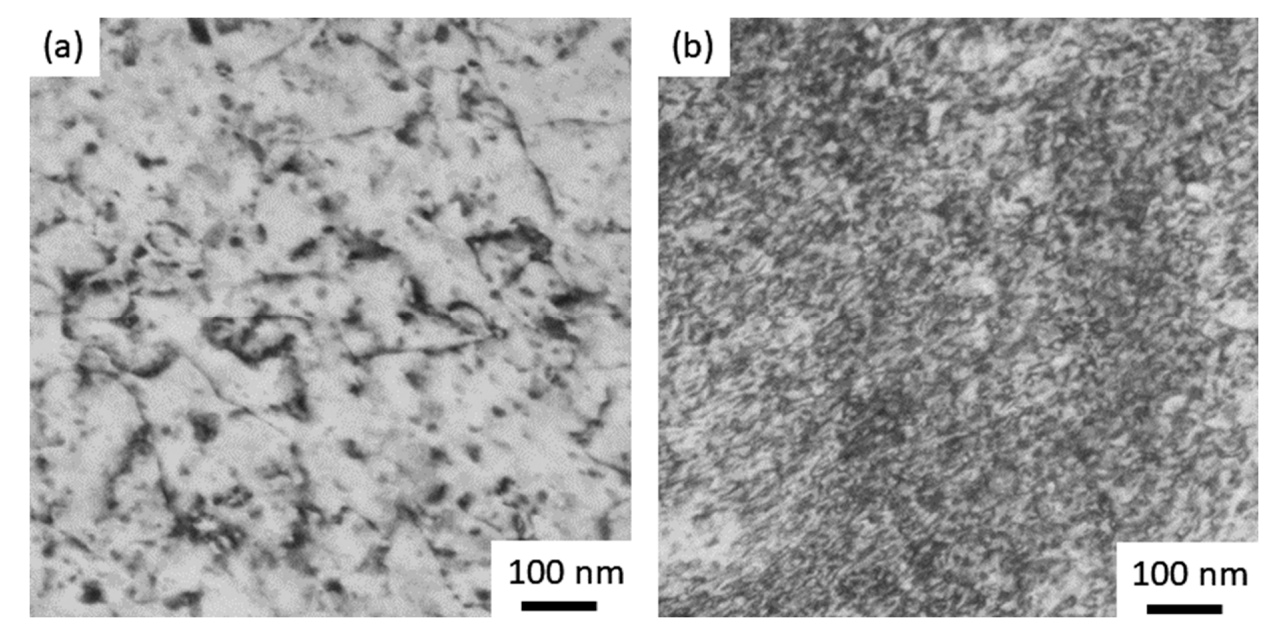

Figure 8. TEM images of weld material (WM) microstructures in laser-welded specimens (with reinforcement) (a) before and (b) after DryLP treatment.

\subsection{Effect of Welding Defects on Fatigue Performance}

During fatigue tests, cracks initiated from undercuts at the weld toe, owing to the reduced hardness and tensile residual stress which remained after welding. The fatigue performances of the as-welded specimens with and without reinforcement were comparable at a stress amplitude of $180 \mathrm{MPa}$, indicating that the stress concentration at undercuts has a greater influence on fatigue performance than stress concentration at the weld toe. The fatigue life of the specimen with the reinforcement removed was shorter than that of the as-welded specimen at a stress amplitude of $120 \mathrm{MPa}$. Small blowholes were observed in the fracture surface of the specimen without reinforcement, which were expected to influence the fatigue performance at lower stress amplitudes. Welding defects, such as undercuts and blowholes, in addition to softening or tensile residual stress, decreased the fatigue life of the welded specimens.

The fatigue performances of the specimens with and without reinforcement after DryLP treatment were improved compared to the equivalent specimens before DryLP treatment, attributed to hardening of the WM up to the value of the original $\mathrm{BM}$ and the introduction of compressive residual stress. The fatigue lives of both specimens after DryLP treatment were significantly increased compared to that of the unpeened welded specimens at lower stress amplitudes. Blowhole defects can lead to stress concentration. However, their contribution is very small, as these features are generally spherical. In addition, the stress concentration at undercuts is smaller at lower stress amplitudes. Therefore, the effect of positive factors induced by DryLP, such as hardening and compressive residual stress, was larger than that of the negative factors, such as stress concentration at undercuts and blowholes at lower stress amplitudes. In addition, for gas metal arc welding lap fillet joint in GA 
590 MPa steel sheets, the blowholes in the WM did not significantly affect the fatigue life at relatively lower stress amplitudes, although the fatigue life decreased in the presence of blowholes and surface pores [40]. Overall, DryLP effectively improved the fatigue performance of laser-welded specimens containing welding defects at lower stress amplitudes.

\subsection{Plastic Deformation Induced by Femtosecond Laser-Driven Shock Wave}

When a peak pressure of a shock wave exceeds a threshold that depends on a material, the pressure increases as a function of the time or the travel distance exhibits a single structure, where the plastic component overtakes the elastic component. The threshold stress for aluminum when the single structure of the shock front is clearly formed is $25 \mathrm{GPa}$ [41]. It was reported that the single structure was observed in the surface layer of $500 \mathrm{~nm}$ in pure aluminum, which was irradiated using the intensity of $8.7 \times 10^{12} \mathrm{~W} / \mathrm{cm}^{2}$ with the pulse duration of $150 \mathrm{fs}$ [42]. Therefore, the shock wave with a single structure over 25 GPa should be driven and propagated in the 2024 aluminum alloy, which was irradiated at the intensity of $1.2 \times 10^{14} \mathrm{~W} / \mathrm{cm}^{2}$ with the pulse duration of $130 \mathrm{fs}$ in this research.

It was empirically observed that the strain rate $\eta$ of the shock wave with the single structure was proportional to the fourth-power of the shock stress $\sigma[43,44]$. For the aluminum alloy, $\eta=9100 \sigma^{4}$ has been reported [41]. Therefore, the strain rate $\eta$ of $3.5 \times 10^{9} \mathrm{~s}^{-1}$ was obtained for the shock stress of $25 \mathrm{GPa}$. The dimensionless Bland number $\mathrm{B}=3 h s \eta / 8 c$ was defined [43], where $h$ is the sample thickness, $c$ is the bulk sound velocity under normal pressure, and $s$ is the slope of the $u_{\mathrm{p}}-u_{\mathrm{s}}$ relation, $u_{\mathrm{s}}=c+s u_{\mathrm{p}}$, where $u_{\mathrm{p}}$ is the particle velocity and $u_{\mathrm{s}}$ is the shock velocity. When $B$ is greater than 1 , steady-wave conditions are expected [41]. The thickness $h$ was estimated to be $3.0 \mu \mathrm{m}$ for $B=1, \eta=3.5 \times 10^{9} \mathrm{~s}^{-1}$, $s=1.338, c=5.328 \mathrm{~km} / \mathrm{s}$ [45]. Therefore, the shock wave with the single structure propagates in the surface layer of $3.0 \mu \mathrm{m}$. The single structure splits into two structures, elastic and plastic waves, at the depth of $3.0 \mu \mathrm{m}$, and the shock wave with the two-wave structure propagates into the deeper region.

Figure 9 shows the hardness in the BM region in the DryLPed 2024 aluminum alloy as a function of the depth measured using nanoindentation (ELIONIX, ENT-1100a, Japan) with an applied load of $1 \mathrm{mN}$ and loading time of $2 \mathrm{~s}$. The increase in hardness is more significant at a depth of $3 \mu \mathrm{m}$ from the surface rather than depths of 3-20 $\mu \mathrm{m}$, although the hardness increased in the surface layer with $20 \mu \mathrm{m}$ thickness. The thickness of the significantly hardened layer of $3 \mu \mathrm{m}$ corresponds to the thickness of $3.0 \mu \mathrm{m}$ where the shock wave with the single structure propagates. This implies that the single structure induces plastic deformation more effectively, thereby increasing the hardness. A high-density-dislocation structure, shown in Figure 8a, was formed in a layer where the shock wave with the single structure propagates, because dislocation generation, rather than dislocation multiplication, was dominant $[9,10,46]$.

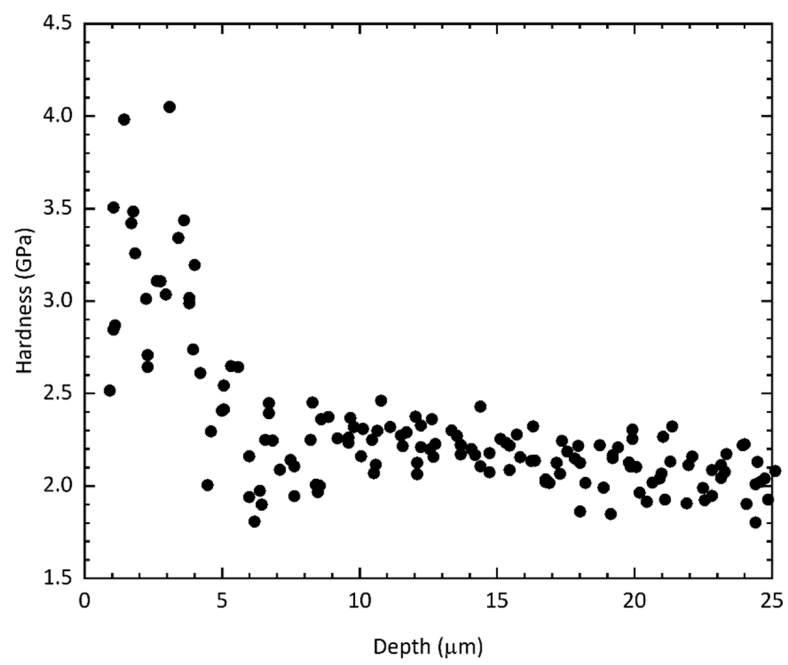

Figure 9. Depth profile of hardness in the BM region in the DryLPed 2024 aluminum measured using nanoindentation. 


\section{Conclusions}

The effects of DryLP on the hardness, residual stress, and fatigue performance of laser-welded 2024-T3 aluminum alloy were investigated. After DryLP treatment, the hardness of the softened WM recovered to that of the original $\mathrm{BM}$, while tensile residual stress in the WM and HAZ changed to compressive stress. DryLP treatment improved the fatigue performances of welded specimens with and without reinforcement almost equally. Positive factors (hardening and introduction of compressive residual stress) induced by DryLP had a larger effect on the mechanical properties than negative factors (stress concentrations near defects at lower stress amplitudes). Therefore, DryLP is expected to be more effective in improving the fatigue performance of laser-welded specimens with weld defects at lower stress amplitudes. Combining high-speed laser welding with DryLP is expected to be a suitable strategy for replacing other welding processes, resulting in high productivity. This combination could be applied in various industrial fields, such as the automotive, rail, aircraft, and space industries.

Author Contributions: This work was supervised by T.S. (Tomokazu Sano). T.S. (Tomokazu Sano) and T.E. conducted all experiments. Y.K. and S.K. supported laser welding experiment. K.A. supported TEM observation. K.M. supported fatigue test. A.S. and T.S. (Takahisa Shobu) supported residual stress measurement. A.H. advised laser welding experiment. Y.S. advised laser peening experiment. T.S. (Takahisa Shobu) wrote the manuscript. All authors discussed the results and commented on the manuscript.

Funding: This work was supported in part by MEXT Quantum Leap Flagship Program (MEXT Q-LEAP) Grant Number JPMXS0118068348, and JSPS KAKENHI Grant Numbers JP16H04247, JP16K14417, and 19K22061. This work was funded in part by ImPACT Program of Council for Science, Technology and Innovation (Cabinet Office, Government of Japan).

Acknowledgments: The laser welding experiment was performed under the Joint Usage/Research Center on Joining and Welding, Osaka University. The synchrotron radiation experiments were performed under the Shared Use Program of JAEA (Proposal Nos. JAEA 2015B-E12, JAEA 2016A-E18, JAEA 2017B-E11, and JAEA 2019A-E07) and QST (Proposal Nos. QST 2016B-H14 and QST 2017A-H18) facilities with the approval of Nanotechnology Platform project supported by the Ministry of Education, Culture, Sports, Science and Technology (Proposal Nos. A-15-AE-0034, A-16-QS-0010, A-16-QS-0026, A-17-QS-0016, A-17-AE-0031, and A-19-AE-0007). The synchrotron radiation experiments were performed using a JAEA experimental station at JAEA beamline BL22XU, SPring-8, with the approval of the Japan Synchrotron Radiation Research Institute (JASRI) (Proposal Nos. 2015B3782, 2016A3783, 2016B3786, 2017A3788, 2017B3737, and 2019A 3737).

Conflicts of Interest: The authors declare no conflict of interest.

\section{References}

1. Anderholm, N.C. Laser-generated stress waves. Appl. Phys. Lett. 1970, 16, 113-115. [CrossRef]

2. Fairand, P.; Wilcox, B.A.; Gallagher, W.J.; Williams, D.N. Laser shock-induced microstructural and mechanical property changes in 7075 aluminum. J. Appl. Phys. 1972, 43, 3893-3895. [CrossRef]

3. Clauer, A.H. Laser Shock Peening, the Path to Production. Metals 2019, 9, 626. [CrossRef]

4. Fabbro, R.; Peyre, P.; Berthe, L.; Scherpereel, X. Physics and applications of laser-shock processing. J. Laser Appl. 1998, 10, 265-279. [CrossRef]

5. Montross, C.S.; Wei, T.; Ye, L.; Clark, G.; Mai, Y.W. Laser shock processing and its effects on microstructure and properties of metal alloys: A review. Int. J. Fatigue 2002, 24, 1021-1036. [CrossRef]

6. Tenaglia, R.D.; Lahrman, D.F. Shock tactics. Nat. Photonics 2009, 3, 267-269. [CrossRef]

7. Sano, Y.; Mukai, N.; Okazaki, K.; Obata, M. Residual stress improvement in metal surface by underwater laser irradiation. Nucl. Instrum. Methods B 1997, 121, 432-436. [CrossRef]

8. Sano, Y.; Obata, M.; Kubo, T.; Mukai, N.; Yoda, M.; Masaki, K.; Ochi, Y. Retardation of crack initiation and growth in austenitic stainless steels by laser peening without protective coating. Mater. Sci. Eng. A 2006, 417, 334-340. [CrossRef]

9. Sano, T.; Eimura, T.; Kashiwabara, R.; Matsuda, T.; Isshiki, Y.; Hirose, A.; Tsutsumi, S.; Arakawa, K.; Hashimoto, T.; Masaki, K.; et al. Femtosecond laser peening of 2024 aluminum alloy without a sacrificial overlay under atmospheric conditions. J. Laser Appl. 2017, 29, 012005. [CrossRef] 
10. Kawashima, T.; Sano, T.; Hirose, A.; Tsutsumi, S.; Masaki, K.; Arakawa, K.; Hori, H. Femtosecond laser peening of friction stir welded 7075-T73 aluminum alloys. J. Mater. Process. Technol. 2018, 262, 111-122. [CrossRef]

11. Trdan, U.; Sano, T.; Klobčara, D.; Sano, Y.; Grum, J.; Šturm, R. Improvement of corrosion resistance of AA2024-T3 using femtosecond laser peening without protective and confining medium. Corros. Sci. 2018, 143, 46-55. [CrossRef]

12. Strickland, D.; Mourou, G. Compression of amplified chirped optical pulses. Opt. Commun. 1985, 56, $219-221$. [CrossRef]

13. Evans, R.; Badger, A.D.; Falliès, F.; Mahdieh, M.; Hall, T.A.; Audebert, P.; Geindre, J.-P.; Gauthier, J.-C.; Mysyrowicz, A.; Grillon, G.; et al. Time- and space-resolved optical probing of femtosecond-laser-driven shock waves in aluminum. Phys. Rev. Lett. 1996, 77, 3359-3362. [CrossRef] [PubMed]

14. Sano, T.; Mori, H.; Ohmura, E.; Miyamoto, I. Femtosecond laser quenching of the $\varepsilon$ phase of iron. Appl. Phys. Lett. 2003, 83, 3498-3500. [CrossRef]

15. Tsujino, M.; Sano, T.; Sakata, O.; Ozaki, N.; Kimura, S.; Takeda, S.; Okoshi, M.; Inoue, N.; Kodama, R.; Kobayashi, K.F.; et al. Synthesis of submicron metastable phase of silicon using femtosecond laser-driven shock wave. J. Appl. Phys. 2011, 110, 126103. [CrossRef]

16. Tsujino, M.; Sano, T.; Ogura, T.; Okoshi, M.; Inoue, N.; Ozaki, N.; Kodama, R.; Kobayashi, K.F.; Hirose, A. Formation of high-density dislocations and hardening in femtosecond-laser-shocked silicon. Appl. Phys. Express 2012, 5, 022703. [CrossRef]

17. Matsuda, T.; Sano, T.; Arakawa, K.; Hirose, A. Multiple-shocks induced nanocrystallization in iron. Appl. Phys. Lett. 2014, 105, 021902. [CrossRef]

18. Matsuda, T.; Sano, T.; Arakawa, K.; Hirose, A. Dislocation structure produced by an ultrashort shock pulse. J. Appl. Phys. 2014, 116, 183506. [CrossRef]

19. Matsuda, T.; Sano, T.; Arakawa, K.; Sakata, O.; Tajiri, H.; Hirose, A. Femtosecond laser-driven shock-induced dislocation structures in iron. Appl. Phys. Express 2014, 7, 122704. [CrossRef]

20. DeWald, A.T.; Rankin, J.E.; Hill, M.R.; Lee, M.J.; Chen, H.L. Assessment of tensile residual stress mitigation in alloy 22 welds due to laser peening. J. Eng. Mater. Technol. 2004, 126, 465-473. [CrossRef]

21. Hatamleh, O.; Lyons, J.; Forman, R. Laser and shot peening effects on fatigue crack growth in friction stir welded 7075-T7351 aluminum alloy joints. Int. J. Fatigue 2007, 29, 421-434. [CrossRef]

22. Hatamleh, O. A comprehensive investigation on the effects of laser and shot peening on fatigue crack growth in friction stir welded AA 2195 joints. Int. J. Fatigue 2009, 31, 974-988. [CrossRef]

23. Sano, Y.; Masaki, K.; Gushi, T.; Sano, T. Improvement in fatigue performance of friction stir welded A6061-T6 aluminum alloy by laser peening without coating. Mater. Des. 2012, 36, 809-814. [CrossRef]

24. Bussu, G.; Irving, P.E. The role of residual stress and heat affected zone properties on fatigue crack propagation in friction stir welded 2024-T351 aluminium joints. Int. J. Fatigue 2003, 25, 77-88. [CrossRef]

25. Liljedahl, C.D.M.; Brouard, J.; Zanellato, O.; Lin, J.; Tan, M.L.; Ganguly, S.; Irving, P.E.; Fitzpatrick, M.E.; Zhang, X.; Edwards, L. Weld residual stress effects on fatigue crack growth behaviour of aluminium alloy 2024-T351. Int. J. Fatigue 2009, 31, 1081-1088. [CrossRef]

26. Nandan, R.; DebRoy, T.; Bhadeshia, H.K.D.H. Recent advances in friction-stir welding-Process, weldment structure and properties. Prog. Mater. Sci. 2008, 53, 980-1023. [CrossRef]

27. Kulekci, C.; Ik, A.S.; Kaluc, E. Effects of tool rotation and pin diameter on fatigue properties of friction stir welded lap joints. Int. J. Adv. Manuf. Technol. 2008, 36, 877-882. [CrossRef]

28. Garware, M.; Kridli, G.T.; Mallick, P.K. Tensile and fatigue behavior of friction-stir welded tailor-welded blank of aluminum alloy 5754. J. Mater. Eng. Perform. 2010, 19, 1161-1171. [CrossRef]

29. Dursun, T.; Soutis, C. Recent developments in advanced aircraft aluminium alloys. Mater. Des. 2014, 56, 862-871. [CrossRef]

30. Schubert, E.; Klassen, M.; Zerner, I.; Walz, C.; Sepold, G. Light-weight structures produced by laser beam joining for future applications in automobile and aerospace industry. J. Mater. Process. Technol. 2001, 115, 2-8. [CrossRef]

31. Katayama, S.; Nagayama, H.; Mizutani, M.; Kawahito, Y. Fibre laser welding of aluminium alloy. Weld. Int. 2009, 23, 744-752. [CrossRef]

32. Shobu, T.; Tozawa, K.; Shiwaku, H.; Konishi, H.; Inami, T.; Harami, T.; Mizuki, J. Wide band energy beamline using Si (111) crystal monochromators at BL22XU in SPring-8. AIP Conf. Proc. 2007, 879, 902-906. [CrossRef] 
33. Shobu, T.; Konishi, H.; Mizuki, J.; Suzuki, K.; Suzuki, H.; Akiniwa, Y.; Tanaka, K. Evaluation of subsurface distribution of residual stress in austenitic stainless steel using strain scanning method. Mater. Sci. Forum 2006, 524, 691-696. [CrossRef]

34. Little, R.E. Estimating the median fatigue limit for very small up-and-down quantal response tests and for S-N data with runouts. In Probabilistic Aspects of Fatigue; Heller, R., Ed.; ASTM International: West Conshohocken, PA, USA, 1972; pp. 29-42.

35. Ahn, J.; Chenb, L.; Heb, E.; Daviesa, C.M.; Deara, J.P. Effect of filler metal feed rate and composition on microstructure and mechanical properties of fibre laser welded AA 2024-T3. J. Manuf. Process. 2017, 25, $26-36$. [CrossRef]

36. Ahn, J.; Heb, E.; Chenb, L.; Deara, J.; Daviesa, C. The effect of Ar and He shielding gas on fibre laser weld shape and microstructure in AA 2024-T3. J. Manuf. Process. 2017, 29, 62-73. [CrossRef]

37. Hu, B.; Richardson, I.M. Autogenous laser keyhole welding of aluminum alloy 2024. J. Laser Appl. 2005, 17, 70-80. [CrossRef]

38. Cross, C.E.; Olson, D.L.; Liu, S. Aluminium Welding, Handbook of Aluminum; Dekker: New York, NY, USA, 2003; Volume 1.

39. Keh, A.S. Direct Observation of Imperfection in Crystals; Interscience Publishers: New York, NY, USA, 1962; pp. 213-233.

40. Kim, D.Y.; Hwang, I.; Jeong, G.; Kang, M.; Kim, D.; Seo, J.; Kim, Y.M. Effect of Porosity on the Fatigue Behavior of Gas Metal ArcWelding Lap Fillet Joint in GA 590 MPa Steel Sheets. Metals 2018, 8, 241. [CrossRef]

41. Crowhurst, J.C.; Armstrong, M.R.; Knight, K.B.; Zaug, J.M.; Behymer, E.M. Invariance of the Dissipative Action at Ultrahigh Strain Rates Above the Strong Shock Threshold. Phys. Rev. Lett. 2011, 107, 144302. [CrossRef]

42. Ashitkov, S.I.; Agranat, M.B.; Kanel, G.I.; Komarov, P.S.; Fortov, V.E. Behavior of Aluminum near an Ultimate Theoretical Strength in Experiments with Femtosecond Laser Pulses. JETP Lett. 2010, 92, 516-520. [CrossRef]

43. Swegle, J.W.; Grady, D.E. Shock viscosity and the prediction of shock wave rise times. J. Appl. Phys. 1985, 58, 692-701. [CrossRef]

44. Grady, D.E. Structured shock waves and the fourth-power law. J. Appl. Phys. 2010, 107, 013506. [CrossRef]

45. McQueen, R.G.; March, S.P.; Taylor, J.W.; Fritz, J.N.; Carter, W.J. High.-Velocity Impact Phenomena; Kinslow, R., Ed.; Academic: New York, NY, USA, 1970; p. 293.

46. Meyers, M.A. A mechanism for dislocation generation in shock-wave deformation. Scr. Metall. 1978, 12, 21-26. [CrossRef] 